\title{
SMALL-SCALE MODEL TESTS ON THE HYDRAULIC STABILITY OF STRUCTURES IN TIDAL WATERWAYS
}

\author{
Theide Wöffler, 1 , Moritz Kreyenschulte ${ }^{1}$, Jan Oetjen ${ }^{1}$, Klemens Uliczka² and Holger \\ Schüttrumpf
}

\begin{abstract}
During the last years, an increased amount of damage has been observed on estuarine and riverine waterway structures such as groins or training walls in tidal waterways. The cause of these damages could be attributed to ship-induced long-periodic waves. Because of higher traffic volumes and increased ship dimensions these loads have risen. In contrast to short-periodic secondary waves, the long-periodic wave system is not taken into account in existing design approaches so far. In the framework of the project "Ship-induced long-periodic loads for the design of cover layers on maritime waterway structures" small-scale 2D physical model tests have been performed in order to quantify the specific overflow and overtopping rate taking into account different geometries, surface roughnesses and permeabilities of the structures as well as stationary overflow, short- and long-periodic waves. Furthermore, the stability of the structures under short- and long-periodic wave loads has been observed. These tests provide the basis for the design of cover layers on river structures in maritime waterways.
\end{abstract}

Keywords: ship induced waves, hydraulic stability

\section{INTRODUCTION}

Estuarine and riverine waterway structures such as groins or training walls are loaded by changing water levels, currents, ice, wind waves and ship waves. These structures are composed of rubble mounds and are often used along German maritime waterways and rivers for coast or bank protection. New research on maritime waterways along the German North and Baltic Sea coast has shown that the influence of ship waves is more important than expected and should not be neglected during the design of these structures (BAW 2012). Figure 1 exemplarily shows the development of damages at groins at Juelssand, Unterelbe, which originate from loading by ship waves.

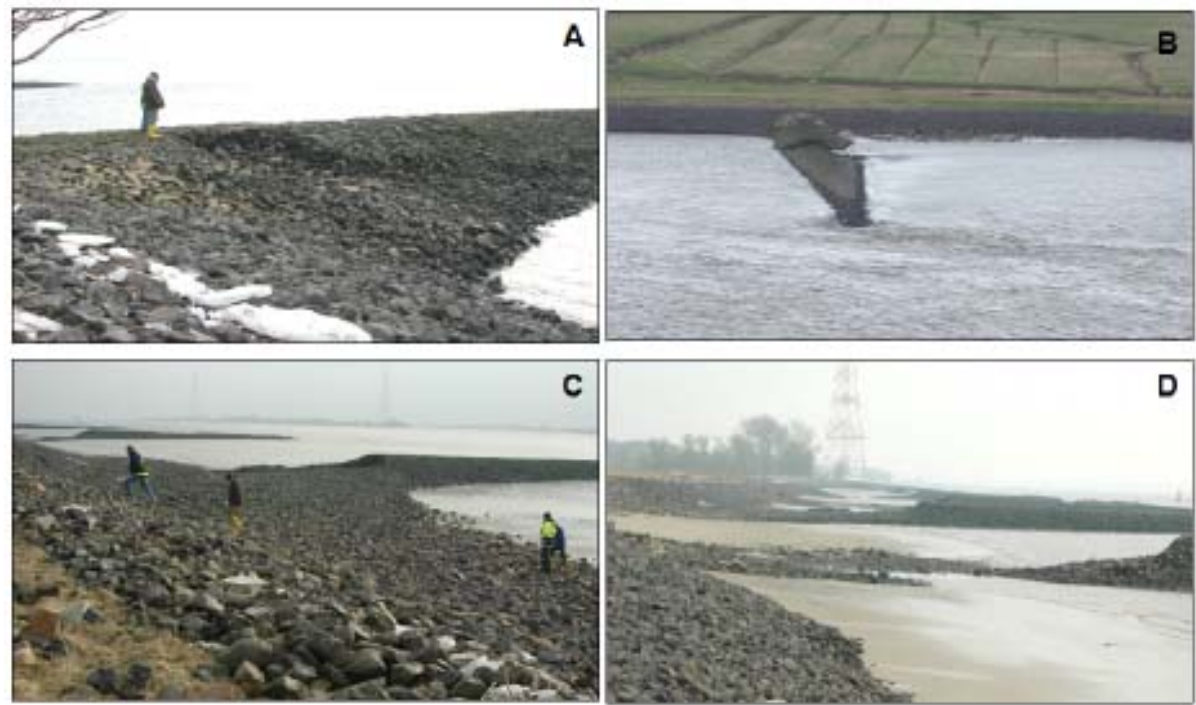

Figure 1. Damage development on groins at Juelssand, Unterelbe (BAW 2012)

In addition, it has been observed that especially long-periodic waves have caused failures and damages. Therefore, a new research programme was initiated to investigate the influence of long-periodic ship waves on estuarine and riverine structures. As the long-periodic wave system is not taken into account in existing design approaches so far this gap of knowledge should be closed in the framework of the project. Both short-periodic and long-periodic wave loads as well as the resulting damage mechanisms are summarized in Figure 2.

1 Institute of Hydraulic Engineering and Water Resources Management, RWTH Aachen University

2 Federal Waterways Engineering and Research Institute, Hamburg 


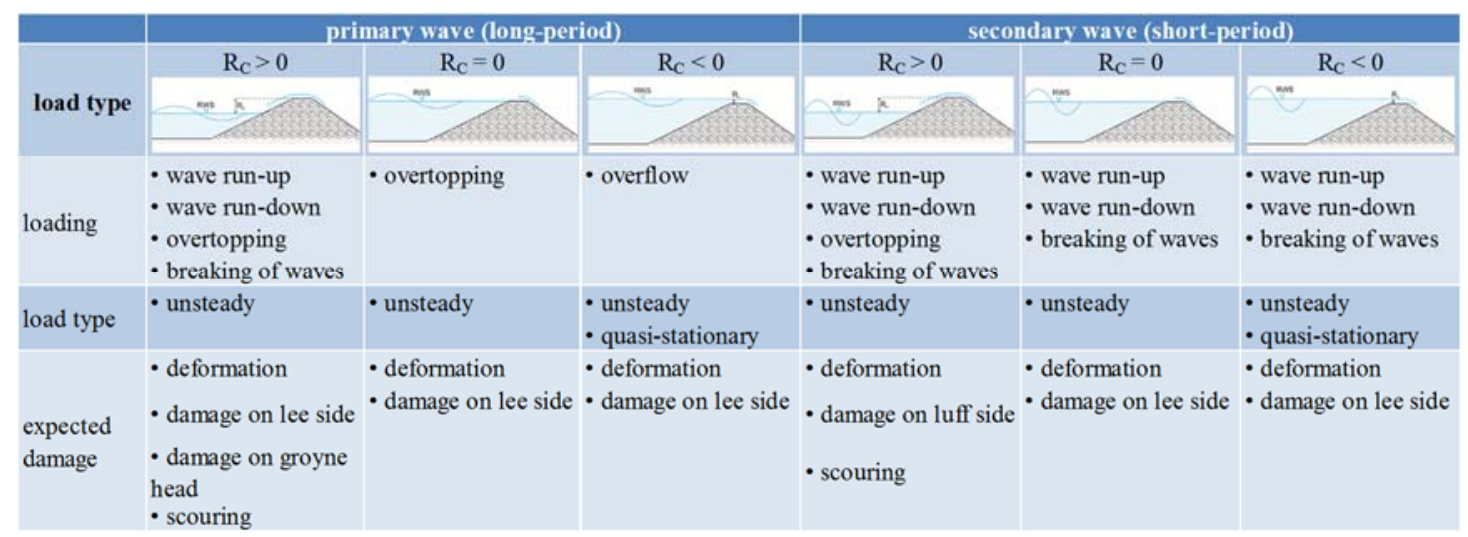

Figure 2. Loads resulting from long-periodic and short-periodic waves depending on freeboard heights

The objective of this project is the development of technically sound and sustainable design approaches that take effects of ship-induced long-periodic waves, currents and overflow loads into account. The project is a collaboration between the Federal Waterways Engineering and Research Institute (BAW), Leichtweiß-Institute for Hydraulic Engineering (LWI) of the Technical University of Braunschweig (TU BS), Institute of Hydraulic Engineering and Water Resources Management (IWW) of the RWTH Aachen University and the Hamburg Port Authority (HPA). The programme is divided into six subprojects:

- SP1: Description of groin failures and damages due to ship waves

- SP2: Synthesis of the available research concerning ship waves and the impact of ship waves on waterway structures

- SP3: Mathematical description of ship waves

- SP4: Experimental research on the influence of ship waves on groin failures

- SP5: Numerical research on the influence of ship waves on groin failures

- SP6: Set-up of new guidelines for the design of waterway structures for long-periodic ship waves.

The present paper focuses on SP4 and gives an overview on small-scale 2D investigations concerning the impact of long-periodic ship waves on the hydraulic stability of waterway structures. Experiments have been performed in 2D in the large current flume of IWW in Aachen for different kinds of structure geometries and hydraulic conditions. In addition, tests with short-periodic waves have been performed in 2D in the wave flume of the LWI in Braunschweig.

The influence of wave dynamics on the overflow volume is investigated in three different test phases. In these three test phases, the general structure of the test models remains constant but the kind of load type changes. The following kinds of loads are investigated during three test phases:

- $\quad$ Test phase 1: steady overflow

- $\quad$ Test phase 2: short-periodic waves

- $\quad$ Test phase 3: long-periodic waves

The influence of the model geometry on overflow and overtopping is investigated by five different models. These model geometries are different with regard to crest width and slope of landward and seaward side. The height of the crest remains constant during all tests. All five models are investigated in all three test phases (see Figure 1). Model 1 is based on the design of a groin root that is used since 1979 at Juelssand, Unterelbe. Model 2 is based on a modified geometry of groin roots at Langlütjen, Außenweser. Model 3 constitutes the geometry of a damaged training wall at Langlütjen with a slope of 1:2 on the luff and lee side. The only difference between model 3 and model 4 is the shortened crest width. The geometry of model 5 is a modified and so far damage-free structure that is used at Langlütjen since 2004. 


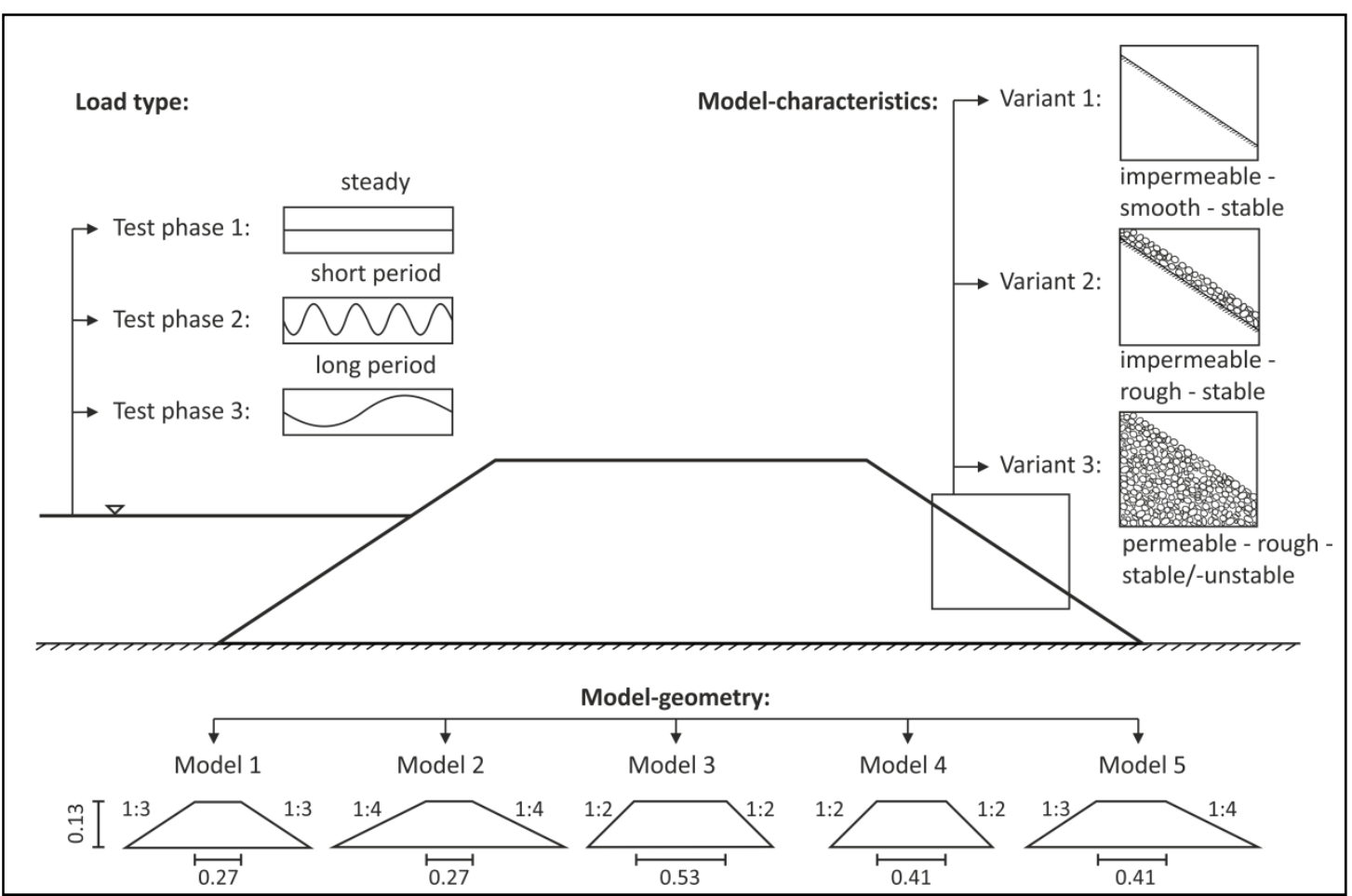

Figure 3. Flow chart of the physical model tests in Subproject 4

The influence of the surface roughness and permeability of the structure is investigated by three different model variants. These three variants are adapted for every model:

- Variant 1: impermeable, smooth and stable

- Variant 2: impermeable, rough and stable

- Variant 3: permeable, rough and stable/unstable

The stability of the models is investigated with the help of the model characteristics in variant 3 during test phase 2 and test phase 3 . The investigation of variant 1 and variant 2 is required for the determination of the fundamental hydraulic flow processes that are quantified by the specific overflow and overtopping rate. Oblique flow cannot be investigated during the test phases. Hence, in every test phase five models with three different variants have been investigated. This results in a total of 45 different model setups.

\section{EXPERIMENTAL SETUP}

\section{Introduction}

Because of the available test facilities, the physical model tests have to be performed in a small scale. The tests are based on Froude model law as the flow is determined by inertial and gravitational forces and free surface flow is present. As the test facilities in the first two test phases have the same width the same models can be investigated in each test phase due to a modular construction. The scaling factor during these tests is determined as shown in equation 1 :

$$
\eta=\frac{L_{N}}{L_{M}}=\frac{h_{N}}{h_{M}}=7.5
$$

The index $\mathrm{N}$ represents values in full scale and the index $\mathrm{M}$ values in model scale. The physical model has no vertical exaggeration. Table 1 lists all scale factors for the experimental setup that are derived from equation 2 :

$$
F r=\frac{v}{\sqrt{g h}} \text { and } F r_{N}=F r_{M}
$$




\begin{tabular}{|lll|}
\hline \multicolumn{3}{|c|}{ Table 1. Scale factors } \\
\hline Value & Dimension & Scale factor \\
\hline Length & $\mathrm{m}$ & $\eta=7.5$ \\
Height & $\mathrm{m}$ & $\eta=7.5$ \\
Slope & - & $\eta=1$ \\
Volume & $\mathrm{m}^{3}$ & $\eta^{3}=421.87$ \\
Flow time & $\mathrm{s}$ & $\sqrt{\eta}=2.74$ \\
Velocity & $\mathrm{m} / \mathrm{s}$ & $\sqrt{\eta}=2.74$ \\
Discharge & $\mathrm{m} 3 / \mathrm{s}$ & $\eta^{2.5}=154.05$ \\
\hline
\end{tabular}

\section{Test Phase 1}

During test phase 1 the models have been loaded by steady overflow. The tests were performed in the large current flume of IWW in Aachen and loading heights have been derived from measurements of long-periodic waves at groins and training walls. Figure 4 gives an overview of the measuring instruments that have been used in test phase 1.

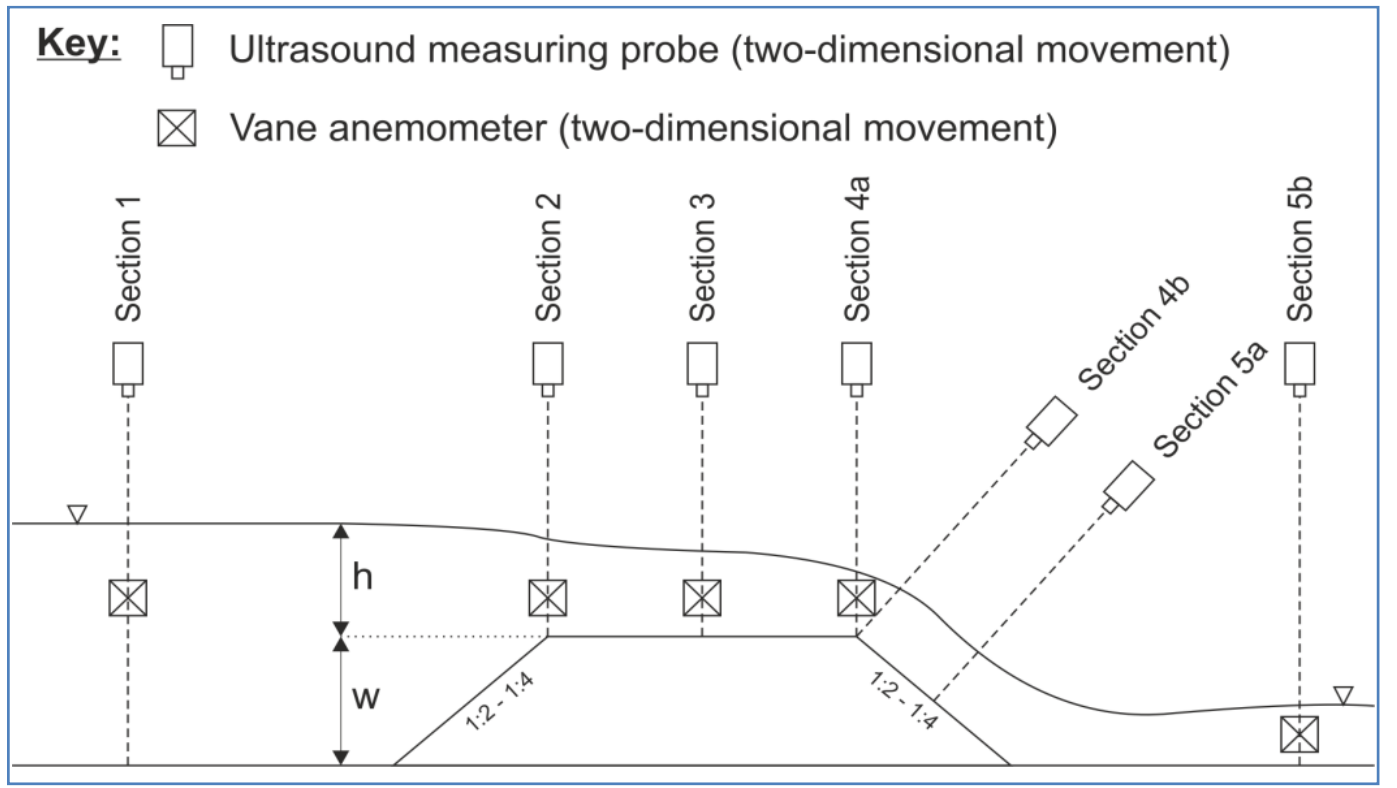

Figure 4. Overview of measuring instruments in test phase 1

Figure 5 shows the realization of the three variants during test phase 1 in the large current flume of IWW.
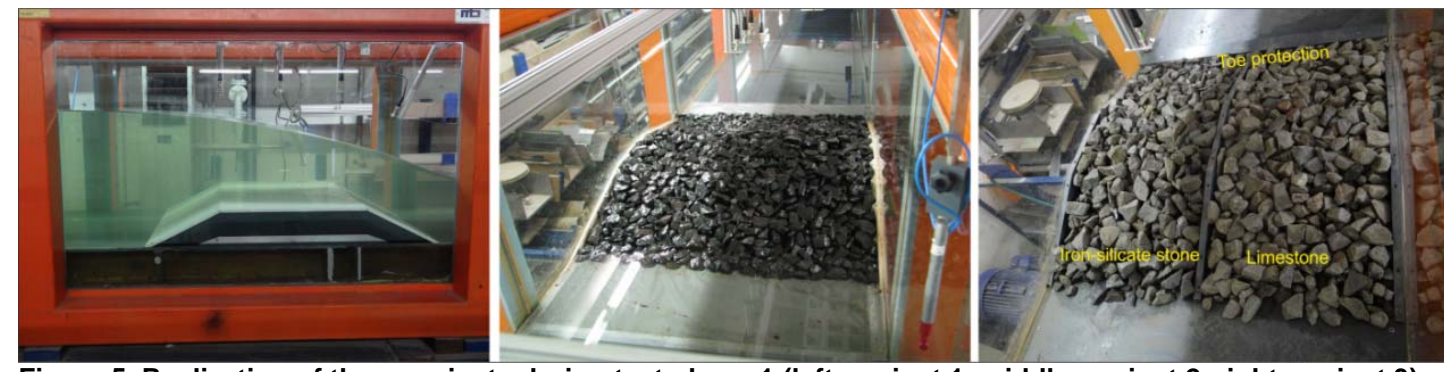

Figure 5. Realization of three variants during test phase 1 (left: variant 1, middle: variant 2, right: variant 3) 
The main objective of test phase 1 is the investigation of the influence of geometry, roughness and permeability on steady overflow. The overflow process can be compared to wave overtopping caused by a wave which period is tending to infinity. In Table 2 the test programme of test phase 1 is listed.

\begin{tabular}{ccc}
\hline \multicolumn{3}{c}{$\begin{array}{c}\text { Table 2. Test programme of test phase 1 } \\
\text { in full scale }\left(\boldsymbol{h}_{\boldsymbol{O}}\right)\end{array}$} \\
$\begin{array}{ccc}\text { and } \\
w / h_{\circ}\end{array}$ & $h_{o}$ & $h_{\text {OM }}$ \\
{$[-]$} & {$[\mathrm{m}]$} & {$[\mathrm{m}]$} \\
\hline 8 & 0.13 & 0.02 \\
4 & 0.25 & 0.03 \\
2 & 0.50 & 0.07 \\
1 & 1.00 & 0.13 \\
0.9 & 1.11 & 0.15 \\
0.8 & 1.25 & 0.17 \\
0.7 & 1.43 & 0.19 \\
0.6 & 1.67 & 0.22 \\
0.5 & 2.00 & 0.27 \\
0.4 & 2.50 & 0.33 \\
\hline
\end{tabular}

\section{Test phase 2}

During test phase 2 the models have been loaded by short-periodic regular waves and JONSWAPspectra. The tests have been performed in a wave flume at LWI in Braunschweig. The wave flume has a total length of $80 \mathrm{~m}$, a width of $1 \mathrm{~m}$ and a height of $1.15 \mathrm{~m}$. Waves can be generated up to a height of $0.3 \mathrm{~m}$ and a period of $4.5 \mathrm{~s}$. During the tests, the average wave overtopping rate for wave periods between $0.8 \mathrm{~s}$ and $2.4 \mathrm{~s}$ has been measured. Because of the identical flume width, the models used in test phase 1 have been transported to Braunschweig and have been used for test phase 2 as well. The dimensions of the wave flume and the test setup are shown in Figure 6.

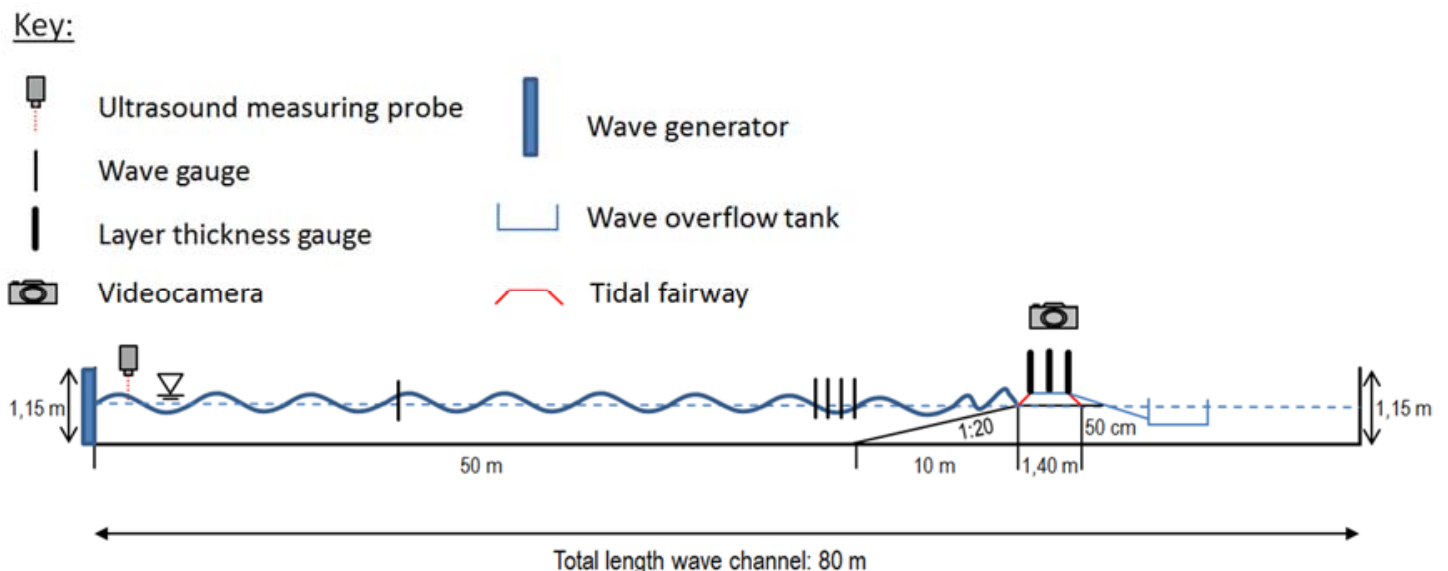

Figure 6. Experimental setup (not to scale) during test phase 2 in the wave flume in Braunschweig

The main objective of test phase 2 is the determination of the influence of geometry and roughness on wave overtopping. Figure 7 shows the realization of each variant within test phase 2.
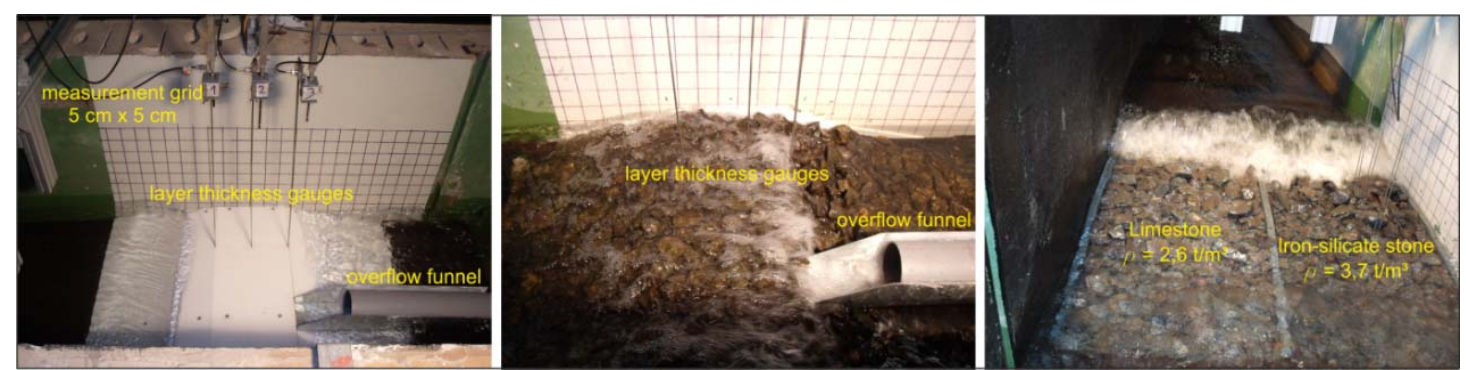

Figure 7. Realization of the models within the second test phase (left: variant 1, middle: variant 2, right: variant 3

In contrast to test phase 1, the test program has been reduced. Only variant 3 has incorporated all models used in test phase 1 . Table 3 shows the modified testing program of test phase 2 . 
Table 3. Modified testing program as used in test phase 2

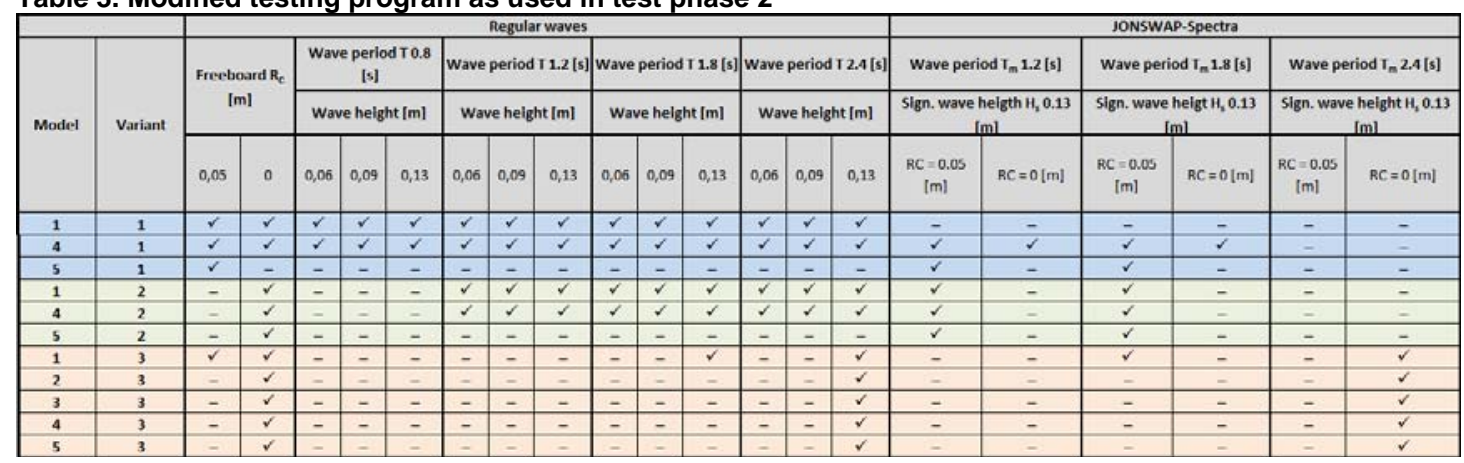

Test phase 3

While the first two test phases focused on steady loads (test phase 1) and short-periodic wave loads (test phase 2), the objective of the third test phase is the determination of the effect of long-periodic wave loads on overtopping discharges. Wave periods between $19 \mathrm{~s}$ and $49 \mathrm{~s}$ and wave heights between $0.12 \mathrm{~m}$ and $0.20 \mathrm{~m}$ have been tested. The experiments in test phase 3 have also been performed in the large current flume (length: $30 \mathrm{~m}$, width $1 \mathrm{~m}$ and depth $1 \mathrm{~m}$ ) in the IWW hydraulic laboratory in Aachen.

\section{RESULTS}

Results of test phase 1

The results of the specific overflow rate of test phase 1 are described using the weir formula by Poleni:

$$
q=\frac{2}{3} \cdot \mu \cdot \sqrt{2 g} \cdot h^{\frac{3}{2}}
$$
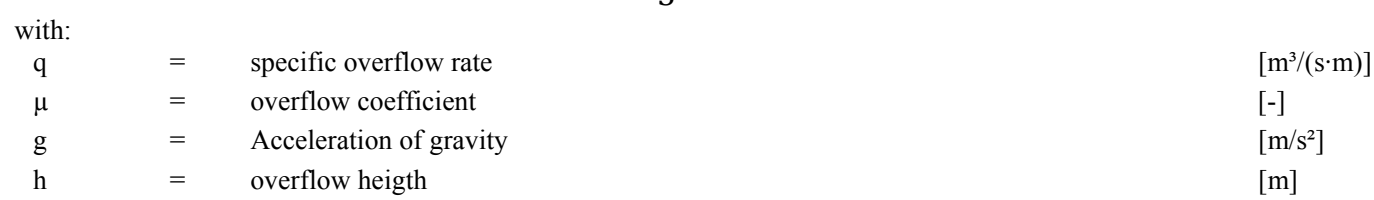

The objective of test phase 1 is the determination of the overflow-coefficient $\mu[-]$, which is part of equation 3. This is necessary to ensure that the overflow equation can be used for groins and training walls in tidal waterways.

Each coefficient represents a certain influence on the overflow and is introduced in the equations as a reduction factor. The influences are separated into geometry, roughness and permeability.

Table 4 shows a summary of the experimental results of test phase 1 . With the presented equations it is possible to calculate the measured overflow of test phase 1 with an average relative deviation of $3.83 \%$.

\begin{tabular}{|l|l|c|}
\hline \multicolumn{2}{|c|}{ Table 4. Summarized modified overflow coefficient for stationary loading } & {$\left[\mathrm{m}^{3} /(\mathrm{s} \cdot \mathrm{m})\right]$} \\
\hline Specific overflow rate: & $q=\frac{2}{3} \cdot \mu_{\text {ges }} \cdot \sqrt{2 g} \cdot h^{\frac{3}{2}}$ & {$[-]$} \\
\hline Modified overflow coefficient: & $\mu_{\text {ges }}=\mu_{\text {ref }} \cdot \mu_{h} \cdot \mu_{R} \cdot \frac{1}{\mu_{D}} \cdot \mu_{L} \cdot \mu_{\text {Luff }} \cdot \mu_{\text {Lee }}$ & {$[-]$} \\
\hline Reference coefficient: & $\mu_{\text {ref }}=0.7$ & {$[-]$} \\
\hline Overflow height coefficient: & $\mu_{h}=0.70 \cdot\left(\frac{h}{w}\right)^{0.41}$ & \\
\hline
\end{tabular}




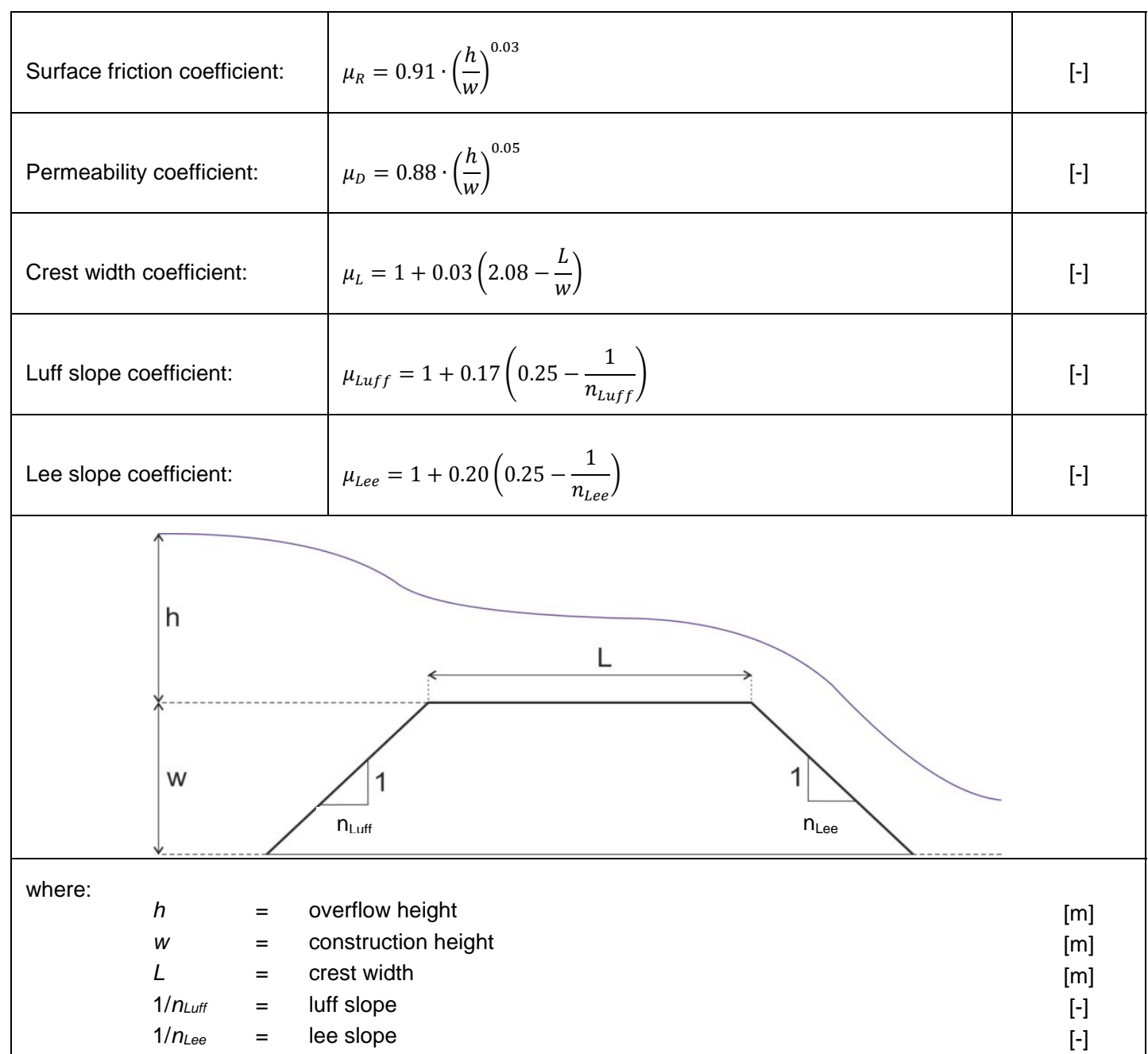

\section{Results of test phase 2}

Studies of wave overtopping rates resulting from regular waves and wave spectra in test phase 2 are based on the following equation (EurOtop 2007):

$$
q_{*}=Q_{0} \cdot e^{\left(-b \cdot R_{*}\right)}
$$

with:

$$
\begin{array}{lll}
q_{*} & = & \text { dimensionless wave overtopping rate } \\
Q_{0} & = & \text { dimensionless wave overtopping rate for } R_{C}=0 \\
b & = & \text { dimensionless coefficient (average wave overtopping rate) } \\
R_{*} & = & \text { dimensionless freeboard height }
\end{array}
$$

where the dimensionless wave overtopping rate and the dimensionless freeboard height are defined as (EurOtop 2007):

$$
\begin{array}{ll}
q_{*}=\frac{q}{\sqrt{g \cdot H_{m 0}^{3}}} \frac{\sqrt{\tan \alpha}}{\xi_{m-1,0}} ; R_{*}=\frac{R_{C}}{\xi_{m-1,0} \cdot H_{m 0}} & \text { for } \xi<2 \\
q_{*}=\frac{q}{\sqrt{g \cdot H_{m 0}^{3}}} ; R_{*}=\frac{R_{C}}{H_{m 0}} & \text { for } \xi>2
\end{array}
$$




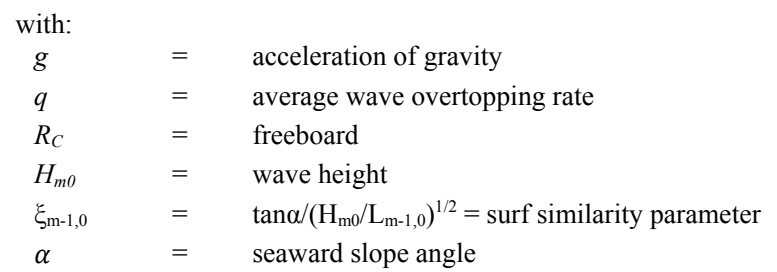

$\left[\mathrm{m} / \mathrm{s}^{2}\right]$

$\left[\mathrm{m}^{3} /(\mathrm{s} \cdot \mathrm{m})\right]$

[m]

[m]

[-]

[]

Figures 9 and 10 show the dimensionless wave overtopping rate of breaking and non-breaking regular waves of models 1 and 4 in variants 1 and 2. By using an exponential regression it is possible to generate a function for the dimensionless wave overtopping rate in form of the basic equation. The Variable $Q_{0}$ represents the wave overtopping rate for the freeboard $R_{C}=0$ and equals the intersection with the y-axis. The variable $b$ describes the gradient of the exponential function. As a result of the additional friction, the freeboard of variant 2 is defined as the modified armor freeboard $A_{C}$ ' (Lioutas et al. 2012). In this case, the crest height of the permeable model is reduced by $90 \%$ of the nominal stone diameter $D_{n 50}$.

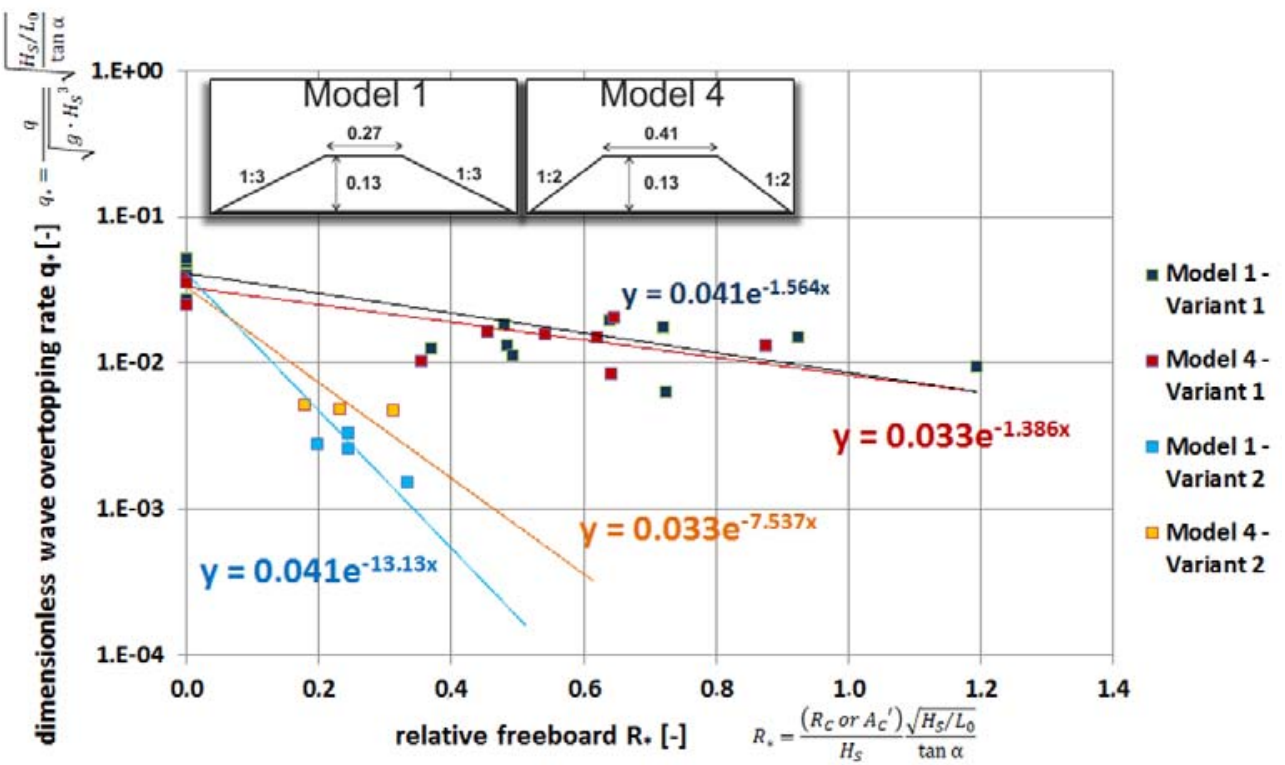

Figure 9. Dimensionless wave overtopping rate for breaking regular waves of variants 1 and 2

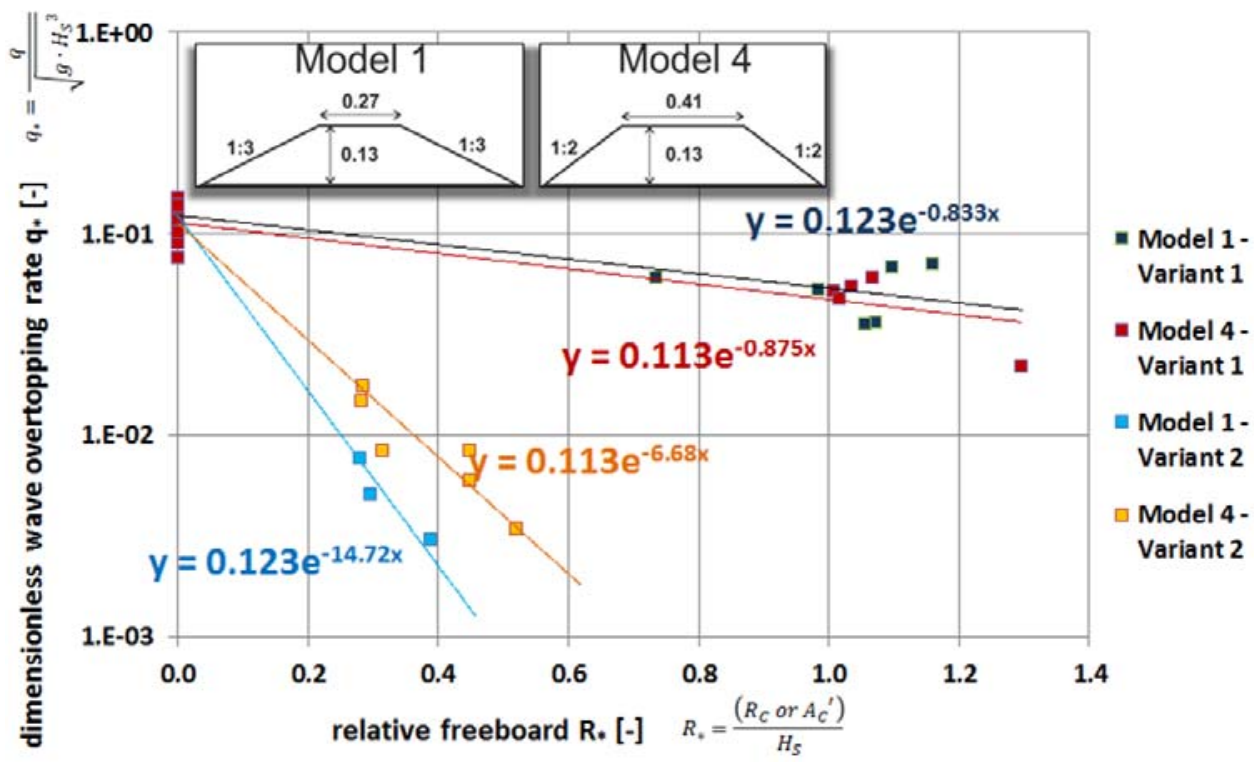

Figure 10. Dimensionless wave overtopping rate for non-breaking regular waves of variants 1 and 2 
The influence of the determined reduction coefficient for the additional friction in variant 2 is calculated as shown in the following equation 7 :

$\begin{array}{llll} & & & \\ & & \\ \text { where: } & & & \\ \gamma_{f} & = & \text { Reduction coefficient for additional friction } & \\ b_{M i V 2} & {[-]} \\ b_{M i V 1} & = & \text { dimensionless coefficient in variant 1 } & {[-]} \\ b_{M i V 2} & = & \text { dimensionless coefficient in variant 2 } & {[-]}\end{array}$

The average wave overtopping rate in variant 2 with additional friction can now be calculated with equation 8:

$$
q_{*}=Q_{0} \cdot e^{\left(-b \cdot R_{*} \cdot \frac{1}{\gamma_{f}}\right)}
$$

Table 5 shows the values of $Q_{0}, b$ and the resulting reduction coefficient $\gamma_{f}$ for models 1,4 and 5 .

Table 5. Summarized overtopping coefficients for short-periodic loading

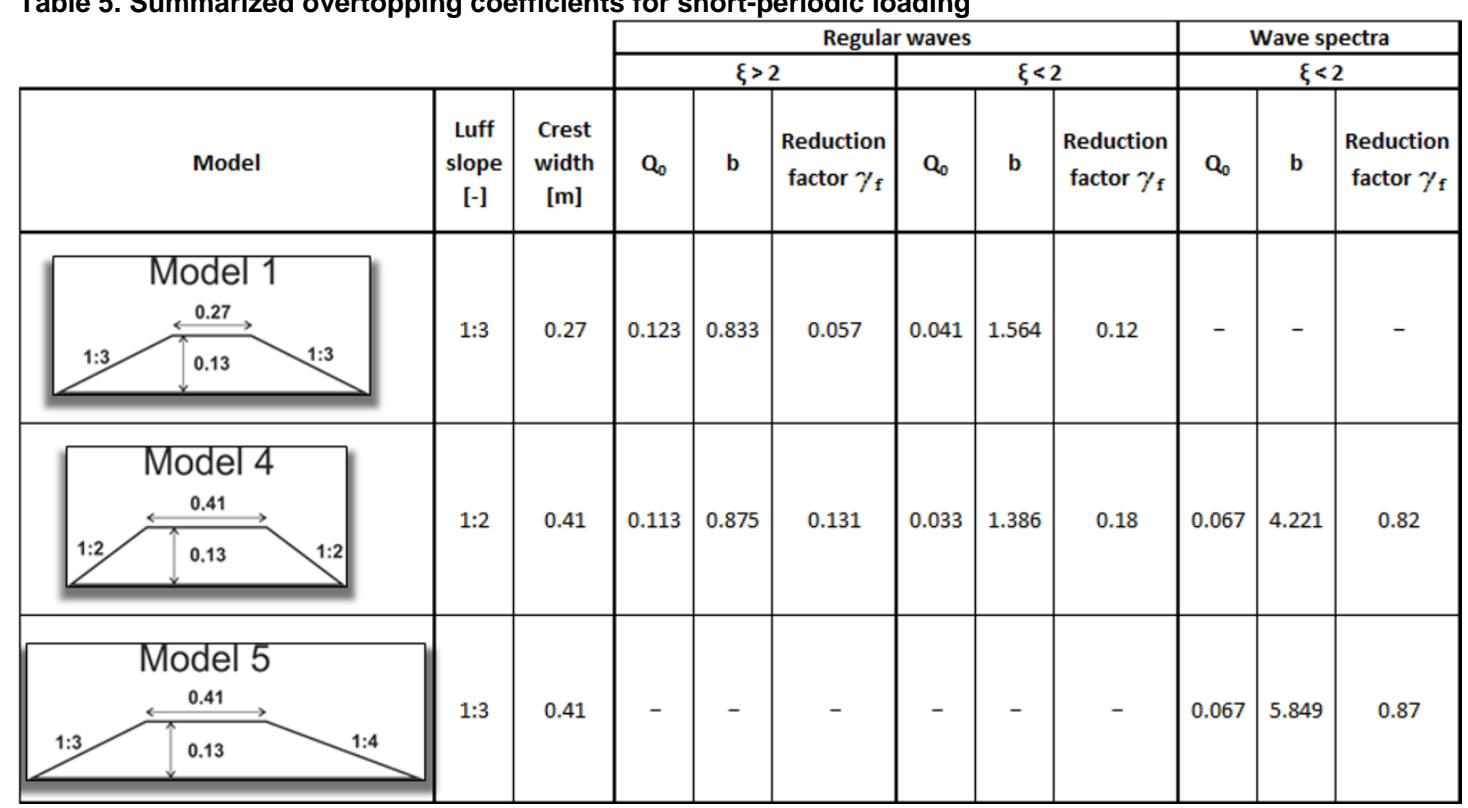

No damage to the construction was observed during test phase 2 .

\section{Results of test phase 3}

In test phase 3 the overflow equation by Poleni (comp. equation 3 ) is extended to take into account the parameters of ship-induced long-periodic waves. Test phase 1 (stationary loading) and test phase 2 (short-periodic wave loading) in terms of the specific overflow/overtopping rate act as boundary conditions for test phase 3 .

As was done in test phase 1 the different parameters influencing the wave overtopping rate are accounted for using the overflow-coefficient $\mu$, in test phase 3 adding the influence of the wave period $T[\mathrm{~s}]$ and wave height $H[\mathrm{~m}]$. Table 5 summarizes the equations to determine the overflow reduction coefficient for long-periodic waves. With the presented equations it is possible to calculate the measured overflow of test phase 3 with an average relative deviation of $3.56 \%$. 


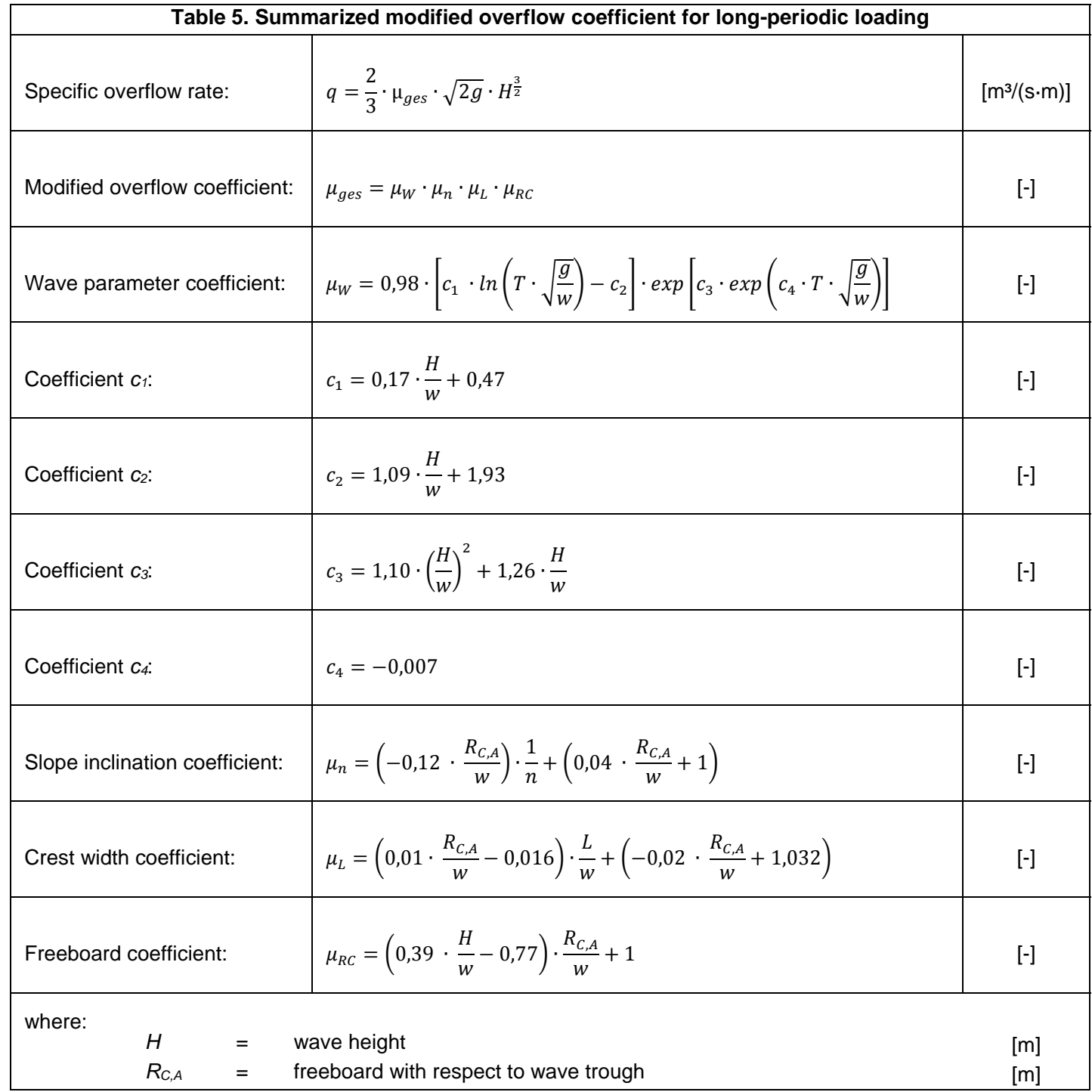

During test phase 3, damage to the construction was observed. Qualitatively, the constructions made of stones with higher density and less inclined slopes performed better than those made of stones with lower density and steeper slopes.

\section{CONCLUSION AND OUTLOOK}

This paper describes the results of small scale 2D physical model tests on the hydraulic stability of structures in tidal waterways within the project "Ship-induced long-period loads for the design of cover layers on river structures in maritime waterways".

The overtopping rate as decisive loading parameter was quantified for all wave forms, i.e. shortperiodic waves, long-periodic waves and stationary loadings. In the test programme the influence of the structural parameters, i.e. geometry, surface roughness and permeability, as well as the influence of wave parameters on the overtopping rate was quantified. For stationary loading and long-periodic wave loading the influence of these parameters is taken into account using reduction coefficients for the overtopping formula of Poleni. For short-periodic waves these parameters are taken into account using the formula for wave overtopping given in EurOtop (2007).

The stability tests show that the waterway constructions are able to resist various ocean swell spectra and regular short-periodic waves while damage can be observed when the structures are loaded by longperiodic waves. This supports the working hypothesis that damage due to hydraulic loading on groins and training walls in tidal waterways is primarily caused by ship-induce long-periodic waves. 


\section{ACKNOWLEDGMENTS}

The authors would like to thank their project partners at the Leichtweiß-Institute for Hydraulic Engineering (LWI), Technical University of Braunschweig, Hamburg Port Authority (HPA) and the Federal Waterways Engineering and Research Institute (BAW).

\section{REFERENCES}

EurOtop. 2007. Die Küste 73. Archiv für Forschung und Technik im Küsteningenieurwesen; Archive for Research and Technology on the North Sea and Baltic Coast; EurOtop - Wave Overtopping of Sea Defences and Related Structures: Assessment Manual.

Federal Waterways Engineering and Research Institute (BAW). 2012. AP1-Schadensanalyse; Hamburg; unpublished.

Gier, F. and H. Schüttrumpf. 2012. AP2-Prozessanalyse; Aachen, Institut für Wasserbau und Wasserwirtschaft (IWW), RWTH Aachen; unpublished.

Lioutas, A., G.M. Smith and H.J. Verhagen. 2012. Spatial Distribution of Overtopping. In: Coastal Engineering Conference; Vol. 33 (1). 